\title{
The inhibitory effect of ghrelin on sepsis-induced inflammation is mediated by the MAPK phosphatase-1
}

\author{
ASHA JACOB, DERRY RAJAN, BETSY PATHICKAL, IMRAN BALOUCH, \\ ADAM HARTMAN, RONGQIAN WU, MIAN ZHOU and PING WANG
}

\begin{abstract}
Laboratory of Surgical Research, Department of Surgery North Shore University Hospital and Long Island Jewish Medical Center, The Feinstein Institute for Medical Research, 350 Community Drive, Manhasset, NY 11030, USA
\end{abstract}

Received September 17, 2009; Accepted October 19, 2009

DOI: 10.3892/ijmm_00000326

\begin{abstract}
Hepatocellular dysfunction occurs early in sepsis and this appears to be caused by Kupffer cell-derived TNF- $\alpha$ production from the liver as a result of the increased release of the sympathetic neurotransmitter, norepinephrine, from the gut. Ghrelin, a novel stomach-derived peptide, is downregulated in sepsis and administration of ghrelin into rodents decrease pro-inflammatory cytokines, attenuates hepatic and other organ injuries and improves survival. Ghrelin's beneficial effect in sepsis is mediated by the inhibition of the sympathetic nervous system (SNS), as evidenced by the reduced gutderived norepineprine (NE) release in sepsis after ghrelin treatment. Recent data suggest that MKP-1, the MAPK phosphatase-1, is involved in the innate immune responses. To determine that the beneficial effect of ghrelin in sepsis is mediated by MKP-1, rats were subjected to sepsis by cecal ligation and puncture (CLP) alone, or treated with ghrelin, beginning at 5-h post-CLP and liver tissues were harvested and examined for MKP-1 mRNA and protein expression. CLP alone produced a significant decrease in MKP-1 gene expression in liver tissues at $20 \mathrm{~h}$ after CLP $(\mathrm{P}<0.05)$. MKP-1 mRNA was decreased by $30-40 \%$ at 2 and $5 \mathrm{~h}$ after CLP, but not statistically significant. MKP-1 protein expression was significantly decreased as early as $2 \mathrm{~h}$ after CLP and remained low at 5-20 h after CLP. While septic rats treated with vehicle produced significant decreases from sham rats, ghrelin treatment improved both mRNA and protein from vehicle group $(0.58 \pm 0.069$ vs. $0.91 \pm 0.16, \mathrm{P}<0.05 ; 0.14 \pm 0.027$ vs $0.22 \pm 0.017, \mathrm{P}=0.013)$, respectively. Since ghrelin's inhibitory effect is mediated by the SNS, we hypothesized that NE treatment in Kupffer cells may downregulate MKP-1. Kupffer cells were treated with NE and examined for MKP-1.
\end{abstract}

Correspondence to: Dr Ping Wang, Laboratory of Surgical Research, The Feinstein Institute for Medical Research, 350 Community Drive, Manhasset, NY 11030, USA

E-mail: pwang@nshs.edu

Key words: ghrelin, sepsis, norepinephrine, MAPK phosphatase-1, inflammation
Treatment with NE for 60 min showed an average of $46.9 \%$ decrease in MKP-1 mRNA expression compared to untreated cells $(\mathrm{P}<0.001)$. Likewise, NE treatment in RAW264.7 cells produced significantly lower MKP-1 mRNA than that of control cells. To further confirm the effect of NE on MKP-1, normal rats were infused with NE for $2 \mathrm{~h}$ through the portal vein and MKP-1 mRNA from the liver was examined. Infusion with NE produced a significant $73.7 \%$ decrease in MKP-1 mRNA. Therefore, ghrelin's inhibitory effect on gut-derived NE release in sepsis leading to the downregulation of proinflammatory cytokines is mediated by MKP-1.

\section{Introduction}

Hepatocellular dysfunction occurs early in sepsis (1) and Kupffer cells, the resident macrophages of the liver, play an important role in this process. This hepatic depression is due to the upregulation of pro-inflammatory cytokines such as TNF- $\alpha$ and IL-1ß in sepsis $(2,3)$. Gut derived norepinephrine release during sepsis is crucial in causing the hepatocellular dysfunction and upregulation of inflammatory cytokines. Studies from our laboratory (4) and Kovarik et al (5) have shown that systemic levels of NE are increased significantly during sepsis. Enterectomy prior to sepsis markedly reduce the circulating level of NE (6). About $50 \%$ of the NE formed in the body is produced by the sympathetic nerve fibers in the gut $(7,8)$. These studies demonstrated that gut is the major source of the increased circulating NE in sepsis. We have also shown that NE induced hepatocellular dysfunction in early sepsis is mediated by the activation of $\alpha 2$-adrenoceptors (9) and recently we reported that the $\alpha_{2 \mathrm{a}}$ form of the receptor mRNA expression is increased in Kupffer cells in response to sepsis (10). In addition, Spengler et al (11) demonstrated that stimulation of $\alpha 2$ adrenoceptors augments the production of macrophage derived TNF- $\alpha$. The mechanism by which NE induced increase in pro-inflammatory cytokines leading to hepatocellular dysfunction is still not known.

Innate immune responses to microbial components activate multiple signaling cascades leading to the activation of the MAPK pathways. These MAPKs participate in the transcription, transport, stabilization and translation of cytokine transcripts. In mammalian cells, MAPK are deactivated by a group of dual specificity protein phosphatases through dephosphorylation of tyrosine and threonine residues critical 
for MAPK activation. These dual specificity protein phosphatases are often referred to as MAPK phosphatases (MKPs). To date, there are at least 10 members of the MKP family; of which, MKP-1 is the most studied. Previous studies using knockout mice have demonstrated that MAPK-phosphatase-1 (MKP-1) play an essential role in the protection of the host against endotoxic shock (12-15). However, it is not known if MKP-1 has any role in NE-induced inflammation in sepsis.

Ghrelin, a novel endogenous ligand for the growth hormone secretagogue receptor 1a (GHSR-1a) is a 28 amino acid peptide first identified in the rat stomach by Kojima et al (16). We have shown that plasma levels of ghrelin decrease significantly in an experimental model of rodent sepsis (17) and ghrelin administration to septic animals decreases proinflammatory cytokines, attenuates organ injury and improves survival $(18,19)$. Intravenous administration of ghrelin significantly reduce the plasma levels of sepsis-induced elevation of NE and TNF- $\alpha$ and the administration of ghrelin receptor antagonist to normal animals results in increased NE and TNF- $\alpha$ (20). This suggests ghrelin has sympathoinhibitory properties and that ghrelin's inhibitory effect on pro-inflammatory cytokines is, in part, due to the modulation of the hyperactive sympathetic nerve activation.

In the present study, we explored the role of MKP-1 in NE-induced upregulation of pro-inflammatory cytokines and to determine whether the inhibitory effect of ghrelin on pro-inflammatory cytokines is mediated by MKP-1.

\section{Materials and methods}

Experimental animals. Male adult Sprague-Dawley rats (250-320 g) purchased from Charles River Laboratories (Wilmington, MA), were used in this study. All rats were housed in a temperature controlled room on a 12-h light/dark cycle and fed a standard Purina rat chow diet for at least one week before experiment. The experiments described herein were carried out in accordance with the Guide for the Care and Use of Laboratory Animals (Institute of Laboratory Animal Resources). This project was approved by the Animal Care and Use Committee of The Feinstein Institute for Medical Research.

Animal model of sepsis. Sepsis was induced by cecal ligation and Puncture (CLP) as previously described by us (19). Briefly, the rats were anesthetized with isoflurane inhalation and a $2-\mathrm{cm}$ ventral midline abdominal incision was performed. The cecum was then exposed, ligated just distal to the ileocecal valve to avoid intestinal obstruction, punctured twice with an 18 -gauge needle, and returned to the abdominal cavity. The incision was then closed in layers. Sham operated animals underwent the same procedure with the exception that the cecum was neither ligated nor punctured. The animals were resuscitated with $3 \mathrm{ml} / 100 \mathrm{~g}$ body weight normal saline subcutaneously immediately after surgery.

Intravenous injection of ghrelin. Five hours after the onset of sepsis, rats were anesthetized with isoflurane inhalation. The right femoral vein was cannulated with a PE-50 catheter. Ghrelin at $4 \mathrm{nmol} / \mathrm{rat}$ or vehicle ( $1 \mathrm{ml}$ normal saline) was administered intravenously over a period of $20 \mathrm{~h}$ through the
Alzet miniosmotic pump. Liver tissues were collected and flash frozen in liquid nitrogen and stored at $-80^{\circ} \mathrm{C}$.

Intraportal infusion of NE in normal rats. Rats were anesthetized with isoflurane inhalation and a $3-\mathrm{cm}$ midline incision was performed. The small intestine was exposed and a branch of the superior mesenteric vein was cannulated with a PE-10 catheter. NE at $20 \mu \mathrm{M}$ in normal saline containing $0.1 \%$ ascorbic acid or vehicle $(0.1 \%$ ascorbic acid in normal saline) was infused into the portal vein at a rate of $13 \mu 1 / \mathrm{min}$ for $2 \mathrm{~h}$ using Harvard pump as described previously (10). Liver tissues were collected, flash frozen in liquid nitrogen and stored at $-80^{\circ} \mathrm{C}$.

Isolation of Kupffer cells. Kupffer cells were isolated from normal rats as previously described $(10,21)$. Briefly, rats were anesthetized with isoflurane inhalation, following midline incision, the portal vein was cannulated and the inferior vena cava was severed. The liver was perfused in situ with $60 \mathrm{ml}$ Hanks balanced salt solution (HBSS) without $\mathrm{Ca}^{2+}$ and $\mathrm{Mg}^{2+}$ at $37^{\circ} \mathrm{C}$ at a rate of $15 \mathrm{ml} / \mathrm{min}$. This was followed by $120 \mathrm{ml}$ of HBSS containing $0.02 \%$ type IV collagenase and $100 \mathrm{mM} \mathrm{CaCl}_{2}$ solution at the same perfusion rate. The liver was then removed en bloc, rinsed with HBSS, minced in HBSS containing collagenase and incubated at $37^{\circ} \mathrm{C}$ for $20 \mathrm{~min}$ to further dissociate the cells. The cell suspension was then passed through a 150 -mesh, stainless steel screen into cold medium containing 10\% FBS. The cells were centrifuged at $50 \mathrm{x}$ g for $2 \mathrm{~min}$ at $4^{\circ} \mathrm{C}$ to sediment hepatocytes. The remaining supernantant was then centrifuged at $450 \mathrm{x} \mathrm{g}$ for $10 \mathrm{~min}$ at $4^{\circ} \mathrm{C}$ and the cell pellet was resuspended in complete medium, layered over a percoll density gradient and centrifuged at $1,000 \times \mathrm{g}$ for $20 \mathrm{~min}$ at $4^{\circ} \mathrm{C}$. The buffy coat consisting Kupffer cells was collected, washed twice and plated at $1-2 \times 10^{6}$ cells in 12 -well dishes and allowed to adhere overnight. Unattached cells were removed by gentle washing.

Cell culture. RAW264.7 cells were obtained from ATCC (Cat: CRL-1548, Manassas, VA), plated in 12-well dishes at a density of $1.0 \times 10^{6}$ cells/well in Dulbecco's minimum essential medium containing heat inactivated $10 \%$ fetal bovine serum (FBS). Cells were incubated in a $5 \% \mathrm{CO}_{2}$ incubator at $37^{\circ} \mathrm{C}$ overnight before treatments.

NE treatment of cells. RAW264.7 cells or Kupffer cells were incubated with $20 \mathrm{nM}$ NE for different time points. RNA was extracted using Tri-reagent (Molecular Research Center, Cincinnati, $\mathrm{OH}$ ) and used for real-time quantitative PCR (Q-PCR) analysis.

MKP-1 mRNA expression by real-time $Q-P C R$. Total RNA $(4 \mu \mathrm{g})$ extracted from either cells or liver tissues were reverse transcribed to cDNA using murine leukemia virus reverse trascriptase (Applied Biosystems). The resulting cDNA was diluted 1:30-fold and the PCR reaction was performed with $2.5 \mu \mathrm{l} \mathrm{cDNA}, 0.2 \mu \mathrm{M}$ each forward and reverse primers, 12.5 $\mu 1 \mathrm{SYBR}$ Green PCR master mix (Applied Biosystems) in a final volume of $25 \mu 1$. The thermal profile for the real-time Q-PCR was $50^{\circ} \mathrm{C}$ for $2 \mathrm{~min}, 95^{\circ} \mathrm{C}$ for $10 \mathrm{~min}$ and followed by 
A

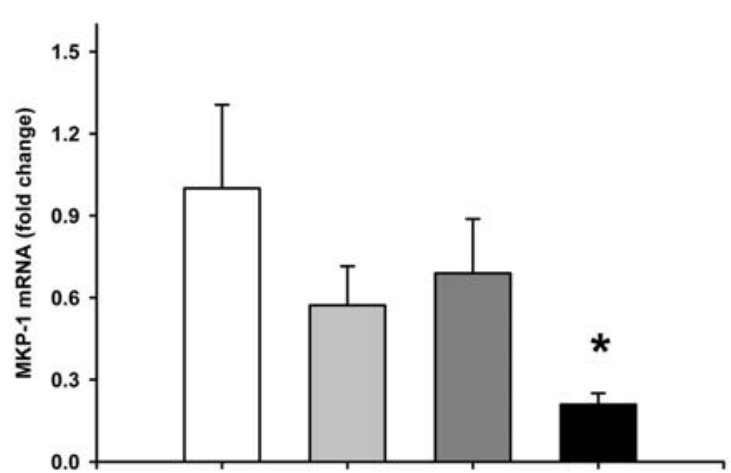

B

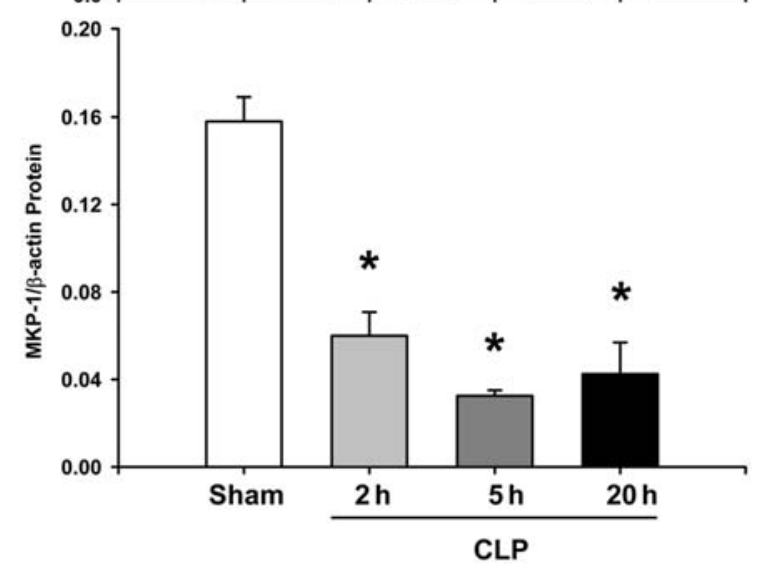

Figure 1. Changes in MKP-1 mRNA and protein in CLP sepsis. (A) RNA was extracted from liver tissues of rats subjected to CLP sepsis. MKP-1 mRNA was evaluated by real-time Q-PCR and presented as fold change over GAPDH. (B) Protein was extracted from the liver and examined for MKP-1 protein by Western blotting using anti-MKP-1 antibody. $\beta$-actin was used as internal control for protein loading. Results are shown as the ratio between MKP-1 and B-actin (MKP-1/B-actin protein). Data are represented as mean \pm SEM and compared by one-way ANOVA and Student-NewmanKeuls method, ${ }^{*} \mathrm{P}<0.05$ versus sham group.

40 cycles of $95^{\circ} \mathrm{C}$ for $15 \mathrm{sec}$ and $60^{\circ} \mathrm{C}$ for $1 \mathrm{~min}$. The gene expression was expressed as fold change from the GAPDH level which is calculated as $2^{-\Delta \Delta C t}$. In addition, melting curve analysis was performed to make sure the specificity of PCR product in this experiment. The following rat primers were used: GAPDH (AF 106860): 5'-ATG ACT CTA CCC ACG GCA AG-3' (forward), 5'-CTG GAA GAT GGT GAT GGG TT-3' (reverse); rat MKP-1 (NM_053769): 5' GCG CGC TCC ACT CAA GTC (forward), 5' GGG CAG GAA GCC GAA AAC 3' (reverse).

$M K P-1$ protein by Western blotting. Total proteins $(50 \mu \mathrm{g})$ from hepatic tissues were loaded on $4-12 \%$ Bis-Tris gels (Invitrogen, Carlsbad, CA) and electrophoretically fractionated in MES-SDS running buffer (Invitrogen). The protein on the gel was then transferred to a $0.45-\mu \mathrm{m}$ nitrocellulose membrane, and blocked with $5 \%$ nonfat dry milk in $10 \mathrm{mM}$ Tris- $\mathrm{HCl}$ with $0.1 \%$ Tween-20, pH 7.5 (TBST). The membrane was incubated with 1:1000 dilution of rabbit anti-MKP-1 polyclonal antibody (C-19: sc-370, Santa Cruz Biotechnology, CA) overnight at $4{ }^{\circ} \mathrm{C}$ followed by incubation in 1:5,000 HRP-linked anti-rabbit IgG for $1 \mathrm{~h}$ at room temperature. Mouse anti- 3 -actin monoclonal antibody (1:10,000; Sigma, St. Louis, MO) was used as the loading control in this experiment. To reveal the reaction bands, the membrane was
A

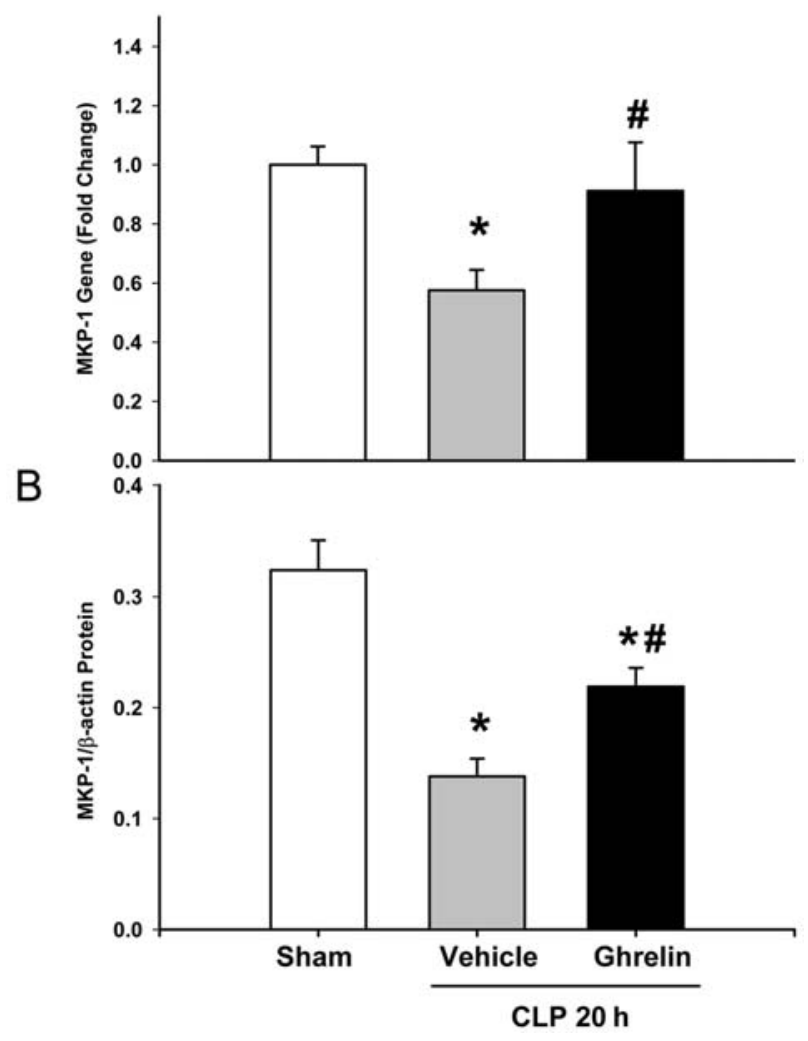

Figure 2. Changes in MKP-1 mRNA and protein in ghrelin treated septic rats. (A) RNA was extracted from liver tissues and examined for MKP-1 mRNA by real-time Q-PCR and presented as fold change over GAPDH. (B) Protein was extracted from the liver and examined for MKP-1 protein by Western blotting using anti-MKP-1 antibody. $\beta$-actin was used as internal control for protein loading. Results are shown as the ratio between MKP-1 and $\beta$-actin (MKP-1/ß-actin protein). Data are represented as mean \pm SEM and compared by one-way ANOVA and Student-Newman-Keuls method, ${ }^{*} \mathrm{P}<0.05$ versus sham group.

reacted with ECL Western blot detection system (Amersham, Piscataway, NJ) and exposed on X-ray film. Bio-Rad GS-800 calibrated densitometer analysis system (Bio-Rad, Hercules, CA) was used to quantitate the Western blots. This system can select the contour of the band, subtract the background and calculate the density.

Statistical analysis. All data were expressed as mean \pm SEM. The statistical analysis methods are one-way ANOVA with Student-Newman-Keuls test. Student's t-test was also used for two group data analysis. Differences in values were considered significant at $\mathrm{P}<0.05$.

\section{Results}

Sepsis induced liver MKP-1 mRNA and protein in rat. To explore the effect of sepsis on MKP-1, rats were subjected to CLP sepsis and liver tissues were harvested at different time points after CLP. Subsequently, RNA and protein were extracted and examined for MKP-1 mRNA and protein by real-time Q-PCR and Western blotting, respectively. CLP produced $79.1 \%$ decrease in MKP-1 mRNA in liver tissues at $20 \mathrm{~h}$ after CLP (1.000 \pm 0.31 vs. $0.209 \pm 0.04, \mathrm{P}<0.05$; Fig. 1A). 


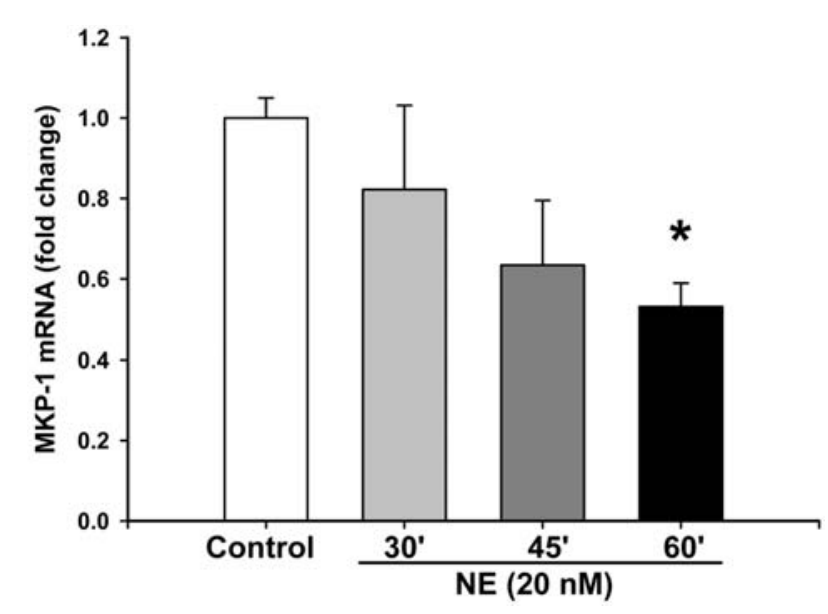

Figure 3. Changes in MKP-1 mRNA in NE treated Kupffer cells. Kupffer cells isolated from normal rats were treated with $20 \mathrm{nM} \mathrm{NE}$ at different time points. RNA was extracted and examined for MKP-1 mRNA by real-time Q-PCR and presented as fold change over GAPDH. Data are represented as mean \pm SEM and compared by one-way ANOVA and Student-NewmanKeuls method, ${ }^{*} \mathrm{P}<0.05$ versus sham group.

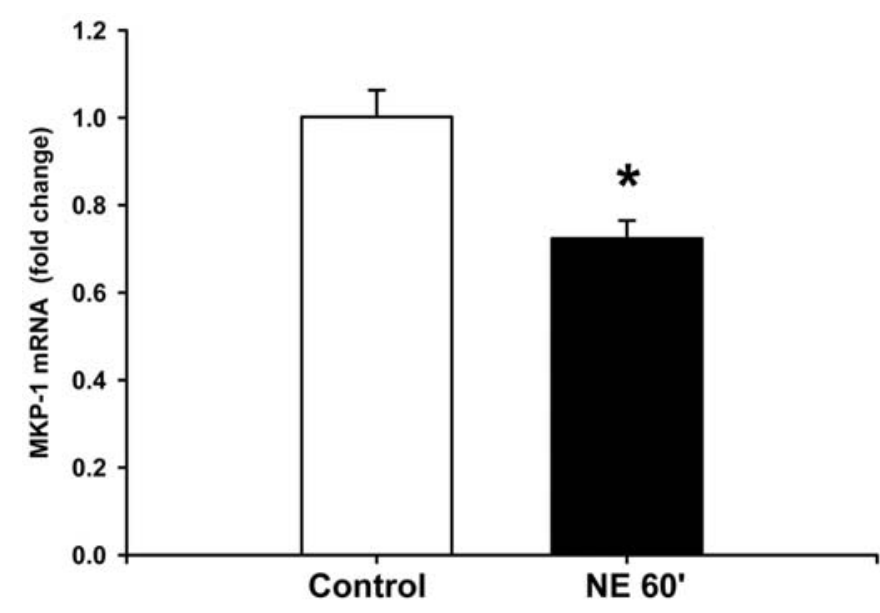

Figure 4. Changes in MKP-1 mRNA in NE treated RAW264.7 cells. RAW cells were treated with $20 \mathrm{nM} \mathrm{NE}$ for $60 \mathrm{~min}$. RNA was extracted and examined for MKP-1 mRNA by real-time Q-PCR and presented as fold change over GAPDH. Data are represented as mean \pm SEM and compared by Student's t-test, ${ }^{*} \mathrm{P}<0.05$ versus sham group.

MKP-1 mRNA was decreased by $30-40 \%$ at 2 and $5 \mathrm{~h}$ after CLP, but not statistically significant. MKP-1 protein was decreased by $62.1 \%$ as early as $2 \mathrm{~h}$ after CLP and remained low at 5 and $20 \mathrm{~h}$ after CLP $(\mathrm{P}<0.001$ vs. Sham; Fig. 1B).

Effect of ghrelin administration on liver MKP-1 $m R N A$ and protein in septic rats. To examine if ghrelin treatment in septic rats can improve MKP-1 mRNA and protein, septic rats were treated with ghrelin 5-h post-CLP. Liver tissues were harvested at $20 \mathrm{~h}$ after CLP and MKP-1 mRNA and protein were determined. While septic rats treated with vehicle produced significant decreases from sham rats, ghrelin treatment improved both mRNA and protein from vehicle group $(0.58 \pm 0.069$ vs. $0.91 \pm 0.16, \mathrm{P}<0.05 ; 0.14 \pm 0.027$ vs. $0.22 \pm 0.017$, $\mathrm{P}=0.013$; Fig. 2A and $\mathrm{B}$ ), respectively.

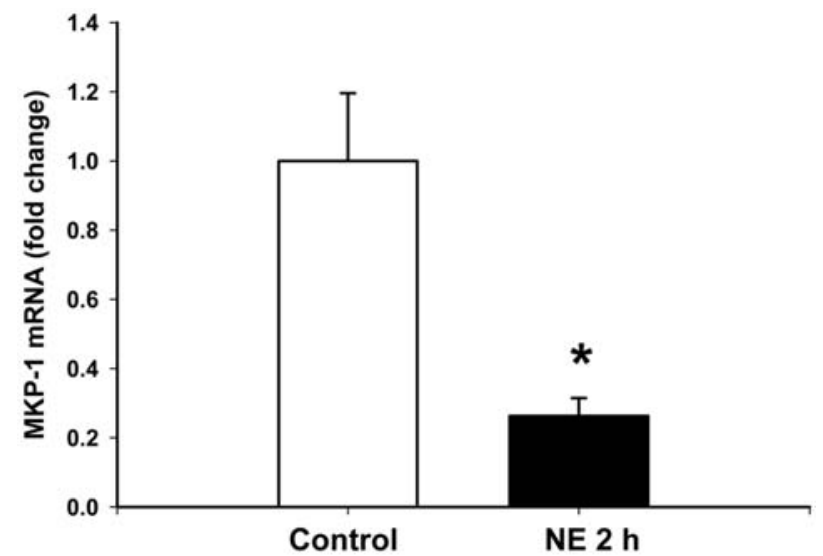

Figure 5. Changes in MKP-1 mRNA in normal rats infused with NE Normal rats were infused with $20 \mathrm{nM} \mathrm{NE}$ for $2 \mathrm{~h}$ through the portal vein. RNA was extracted from liver tissues and examined for MKP-1 mRNA by real-time Q-PCR and presented as fold change over GAPDH. Data are represented as mean \pm SEM and compared by Student's t-test, ${ }^{*} \mathrm{P}<0.05$ versus sham group.

Effect of NE treatment on MKP-1 mRNA in Kupffer cells and $R A W 264.7$ cells. We have recently shown that increased expression of the $\alpha_{2 \mathrm{~A}}$ adrenoceptor, a known receptor for NE, in Kupffer cells could be responsible for the NE-induced inflammation in sepsis (10). To explore the effect of NE treatment on MKP-1 mRNA, we isolated Kupffer cells, treated with NE and examined for MKP-1. Kupffer cells treated with $\mathrm{NE}$ for $60 \mathrm{~min}$ produced $46.9 \%$ decrease in MKP-1 mRNA ( $1.00 \pm 0.050$ vs. $0.531 \pm 0.06, \mathrm{P}<0.001$; Fig. 3 ). Kupffer cells treated with NE for 30 and 45 min exhibited a slight decrease in MKP-1 mRNA, but no significant decrease was observed. Likewise, RAW cells treated with NE for 60 min also produced significant decrease in MKP-1 mRNA (P=0.02; Fig. 4).

Effect of intraportal infusion of NE on MKP-1. To determine whether the downregulation of MKP-1 mRNA observed in vitro could also be evident in vivo, normal rats were infused continuously with NE through the portal vein for $2 \mathrm{~h}$ and liver tissues were examined for MKP-1 mRNA. Interestingly, NE infusion for $2 \mathrm{~h}$ produced $73.7 \%$ decrease in MKP-1 mRNA $(\mathrm{P}=0.014$; Fig. 5).

\section{Discussion}

The objective of our study was to first determine if MKP-1 plays any role in NE-induced inflammation in sepsis-associated hepatocellular dysfunction. Second, if the beneficial effect of ghrelin in downregulating pro-inflammatory cytokines in the liver during sepsis was mediated by MKP-1. In order to answer these questions, we examined MKP-1 mRNA and protein in liver tissues following CLP. Our results clearly showed that MKP-1 mRNA was significantly downregulated in $20 \mathrm{~h} \mathrm{CLP}$ sepsis (i.e., late sepsis). However, we observed an average $30-40 \%$ decrease in MKP-1 mRNA at earlier time points, though no significant difference was evident from the sham group. In contrast, MKP-1 protein was significantly decreased as early as $2 \mathrm{~h}$ and remained low at 5 and $20 \mathrm{~h}$ after CLP. Ghrelin treatment in septic rats partially restored both MKP-1 
mRNA and protein. This suggests that ghrelin's beneficial effect in sepsis is, in part, mediated by MKP-1.

It has been documented that CLP sepsis upregulates proinflammatory cytokines such as TNF- $\alpha$ IL- $1 \beta$ and IL- 6 in the liver which leads to hepatocellular dysfunction (2). Gutderived NE release during sepsis is crucial in causing hepatocellular dysfunction and upregulation of inflammatory cytokines (6). Circulating levels of NE increase significantly during sepsis and during the early stage of sepsis, NE levels in the portal blood reaches $\sim 20 \mathrm{nM}$ (6). Therefore, we further explored if $20 \mathrm{nM}$ NE treatment in Kupffer cells can alter MKP-1. Treatment with NE for 60 min significantly decreased MKP-1 mRNA. Similar treatment in RAW cells also significantly decreased MKP-1 mRNA. In addition, NE infusion, in normal rats, through the portal vein for $2 \mathrm{~h}$ which delivered $20 \mathrm{nM} \mathrm{NE}$ into the portal circulation also significantly decreased MKP-1. This suggests that NE induced inflammation in Kupffer cells and other macrophages downregulate MKP-1. Previously, we demonstrated that ghrelin treatment in sepsis reduced NE levels and decreased TNF- $\alpha$ production (20). In the present study, we showed that the observed decrease in TNF- $\alpha$ following ghrelin treatment in sepsis could be mediated by MKP-1.

How does the downregulation of MKP-1 in the liver affect pro-inflammatory cytokines leading to hepatocellular dysfunction? Interaction of immune cells with microbial components interacts with Toll-like receptors (TLRs) and activates downstream signaling through four adaptor proteins, MYD88, TIRAP, TRIF and TRAM. This leads to the activation of NFKB and MAPK pathways. MAPK such as extracellular signal-regulated kinases (ERK), c-Jun N-terminal kinases (JNK) and p38 enhance the expression of pro-inflammatory cytokines such as TNF- $\alpha$ through both transcriptional and posttranscriptional mechanisms. Growth factors preferentially activate the ERK pathway, whereas, stress and inflammatory cytokines activate the JNK and p38 pathways $(22,23)$. These MAPK pathways are activated through phosphorylation, thus dephosphorylation of MAPKs by phosphatases is likely the most efficient mode of negative regulation. MKP-1 is the first identified MAPK phosphatase that has been well studied in a number of cell systems. The mouse MKP-1 cDNA was identified in the $1980 \mathrm{~s}$ and encodes a protein of $40 \mathrm{kDa}(24)$. Shortly after, the human homologue was identified (25). These proteins exhibited high selectivity towards the ERK MAPK suggesting an important feedback control for the ERK MAPKs (26-29). Since it was the first phosphatase found to be specific for the MAPK, selectively targeting phosphotyrosine and phosphothreonine residues, it was named MAPK phosphatase-1 or MKP-1. Subsequent studies provided compelling evidence that MKP-1 preferentially deactivates stress MAPKs such as p38 and JNK $(30,31)$. Thus, significant decrease of MKP-1 mRNA and protein as observed in NE-induced inflammation and sepsis can result in the increased activation of JNK and p38 leading to the overproduction of pro-inflammatory cytokines from the liver and thus results in hepatocellular dysfunction.

How NE downregulates MKP-1 in sepsis which leads to hepatic depression and how ghrelin inhibits this decrease in MKP-1 remain to be understood. The MKP-1 activity can be regulated at many levels. First, MKP-1 expression can be induced by growth factors and stress and this induction by extracellular stimuli occurs independently of de novo protein synthesis (24). In response to extracellular stimuli, MKP-1 mRNA levels are often increased by 10-100-fold within 15 to $60 \mathrm{~min}$. The stability of MKP-1 mRNA does not change indicating that the induction of MKP-1 expression is primarily mediated by transcriptional mechanism. Chen et al demonstrated that RAW264.7 macrophages stimulated with LPS resulted in the increased activity of JNK and p38 and these activities reached peak levels within $15 \mathrm{~min}$ of exposure and returned to basal levels within $60 \mathrm{~min}$, while the MKP-1 protein levels were increased dramatically from undetectable levels. This increase in MKP-1 protein correlated closely with the deactivation of JNK and p38 (32). Our results show that MKP-1 mRNA is significantly downregulated in the liver during sepsis and this downregulation is primarily in response to NE on the Kupffer cells. In addition, ghrelin treatment during sepsis improved MKP-1 mRNA to near basal level suggesting that ghrelin can prevent the downregulation of MKP-1 that was observed in sepsis. This indicates that the regulation of MKP-1 by ghrelin could be at the transcriptional level. Further studies are needed to confirm this observation.

Second, the stability of MKP-1 protein can be altered by phosphorylation. It has been well documented that MKP-1 protein is degraded by the ubiquitin-directed proteasome complex (33). MKP-1 can be phosphorylated by both ERK and JNK $(33,34)$. Phosphorylation by ERK inhibits ubiquitin mediated degradation of MKP-1 whereas, JNK phosphorylation enhances the degradation of MKP-1 (34).

Third, acetylation of MKP-1 protein has been emerged recently as another means of MKP-1 regulation. Cao et al (35) showed that MKP-1 protein is acetylated on lysine 57 residue in macrophages in response to LPS. This acetylation of MKP-1 neither affects its protein stability nor alters its intrinsic phosphatase activity; rather, acetylation potentiates its interaction with p38 leading to efficient deactivation of the p38 protein.

In the present study, we showed that the MKP-1 mRNA and protein are significantly decreased in sepsis. This decrease is primarily caused by the increase in NE release during sepsis which then leads to exaggerated production of proinflammatory cytokines in the liver leading to hepatocellular dysfunction. We also showed that ghrelin's inhibitory effect in sepsis is mediated by MKP-1. Future studies await to determine the exact mechanism by which NE downregulates MKP-1 and if such factors are involved in the protective effect of ghrelin on MKP-1

\section{Aknowledgements}

This study was supported by the National Institute of Health grant No. R01 GM53008 and R01 GM57468 (P. Wang). The authors would like to thank Dr Steve Blau and the members of the surgical research team for their excellent discussions and suggestions for this project.

\section{References}

1. Wang P, Ba ZF and Chaudry IH: Hepatocellular dysfunction occurs earlier than the onset of hyperdynamic circulation during sepsis. Shock 3: 21-26, 1995. 
2. Koo DJ, Chaudry IH and Wang P: Kupffer cells are responsible for producing inflammatory cytokines and hepatocellular dysfunction during early sepsis. J Surg Res 83: 151-157, 1999.

3. Yang S, Zhou M, Fowler DE and Wang P: Mechanisms of the beneficial effect of adrenomedullin and adrenomedullin-binding protein-1 in sepsis: down-regulation of proinflammatory cytokines. Crit Care Med 30: 2729-2735, 2002.

4. Hahn PY, Wang P, Tait SM, Ba ZF, Reich SS and Chaudry IH: Sustained elevation in circulating catecholamine levels during polymicrobial sepsis. Shock 4: 269-273, 1995.

5. Kovarik MF, Jones SB and Romano FD: Plasma catecholamines following cecal ligation and puncture in the rat. Circ Shock 22: 281-290, 1987

6. Yang S, Koo DJ, Zhou M, Chaudry IH and Wang P: Gut-derived norepinephrine plays a critical role in producing hepatocellular dysfunction during early sepsis. Am J Physiol Gastrointest Liver Physiol 279: G1274-G1281, 2000.

7. Eisenhofer G, Aneman A, Hooper D, Holmes C, Goldstein DS and Friberg P: Production and metabolism of dopamine and norepinephrine in mesenteric organs and liver of swine. Am J Physiol 268: G641-G649, 1995.

8. Eisenhofer G, Aneman A, Hooper D, Rundqvist B and Friberg P: Mesenteric organ production, hepatic metabolism, and renal elimination of norepinephrine and its metabolites in humans. J Neurochem 66: 1565-1573, 1996.

9. Yang S, Zhou M, Chaudry IH and Wang P: Norepinephrineinduced hepatocellular dysfunction in early sepsis is mediated by activation of alpha2-adrenoceptors. Am J Physiol Gastrointest Liver Physiol 281: G1014-G1021, 2001.

10. Miksa M, Das P, Zhou M, et al: Pivotal role of the alpha(2A)adrenoceptor in producing inflammation and organ injury in a rat model of sepsis. PLoS One 4: E5504, 2009.

11. Spengler RN, Allen RM, Remick DG, Strieter RM and Kunkel SL: Stimulation of alpha-adrenergic receptor augments the production of macrophage-derived tumor necrosis factor. J Immunol 145: 1430-1434, 1990.

12. Zhao Q, Wang X, Nelin LD, et al: MAP kinase phosphatase 1 controls innate immune responses and suppresses endotoxic shock. J Exp Med 203: 131-140, 2006.

13. Hammer M, Mages J, Dietrich H, et al: Dual specificity phosphatase 1 (DUSP1) regulates a subset of LPS-induced genes and protects mice from lethal endotoxin shock. J Exp Med 203: $15-20,2006$.

14. Salojin KV, Owusu IB, Millerchip KA, Potter M, Platt KA and Oravecz T: Essential role of MAPK phosphatase-1 in the negative control of innate immune responses. J Immunol 176: 1899-1907, 2006.

15. Chi H, Barry SP, Roth RJ, et al: Dynamic regulation of pro- and anti-inflammatory cytokines by MAPK phosphatase 1 (MKP-1) in innate immune responses. Proc Natl Acad Sci USA 103: 2274-2279, 2006.

16. Kojima M, Hosoda H, Date Y, Nakazato M, Matsuo H and Kangawa K: Ghrelin is a growth-hormone-releasing acylated peptide from stomach. Nature 402: 656-660, 1999.

17. Wu R, Zhou M, Cui X, Simms HH and Wang P: Upregulation of cardiovascular ghrelin receptor occurs in the hyperdynamic phase of sepsis. Am J Physiol Heart Circ Physiol 287: H1296-H1302, 2004.

18. Wu R, Dong W, Cui X, et al: Ghrelin down-regulates proinflammatory cytokines in sepsis through activation of the vagus nerve. Ann Surg 245: 480-486, 2007.

19. Wu R, Dong W, Zhou M, Cui X, Hank Simms H and Wang P: Ghrelin improves tissue perfusion in severe sepsis via downregulation of endothelin-1. Cardiovasc Res 68: 318-326, 2005.
20. Wu R, Zhou M, Das P, et al: Ghrelin inhibits sympathetic nervous activity in sepsis. Am J Physiol Endocrinol Metab 293: E1697-E1702, 2007.

21. Wang P, Ba ZF and Chaudry IH: Mechanism of hepatocellular dysfunction during early sepsis. Key role of increased gene expression and release of proinflammatory cytokines tumor necrosis factor and interleukin-6. Arch Surg 132: 364-370, 1997.

22. Liu Y, Shepherd EG and Nelin LD: MAPK phosphatases regulating the immune response. Nat Rev Immunol 7: 202-212, 2007.

23. Li L, Chen SF and Liu Y: MAP kinase phosphatase-1, a critical negative regulator of the innate immune response. Int J Clin Exp Med 2: 48-67, 2009.

24. Lau LF and Nathans D: Identification of a set of genes expressed during the G0/G1 transition of cultured mouse cells. EMBO J 4: 3145-3151, 1985

25. Keyse SM and Emslie EA: Oxidative stress and heat shock induce a human gene encoding a protein-tyrosine phosphatase. Nature 359: 644-647, 1992.

26. Charles CH, Sun H, Lau LF and Tonks NK: The growth factorinducible immediate-early gene $3 \mathrm{CH} 134$ encodes a proteintyrosine-phosphatase. Proc Natl Acad Sci USA 90: 5292-5296, 1993.

27. Alessi DR, Smythe C and Keyse SM: The human CL100 gene encodes a Tyr/Thr-protein phosphatase which potently and specifically inactivates MAP kinase and suppresses its activation by oncogenic ras in Xenopus oocyte extracts. Oncogene 8: 2015-2020, 1993

28. Zheng CF and Guan KL: Dephosphorylation and inactivation of the mitogen-activated protein kinase by a mitogen-induced Thr/Tyr protein phosphatase. J Biol Chem 268: 16116-16119, 1993.

29. Sun H, Charles CH, Lau LF and Tonks NK: MKP-1 (3CH134), an immediate early gene product, is a dual specificity phosphatase that dephosphorylates MAP kinase in vivo. Cell 75: 487-493, 1993

30. Liu Y, Gorospe M, Yang C and Holbrook NJ: Role of mitogenactivated protein kinase phosphatase during the cellular response to genotoxic stress. Inhibition of c-Jun N-terminal kinase activity and AP-1-dependent gene activation. J Biol Chem 270: 8377-8380, 1995.

31. Raingeaud J, Gupta S, Rogers JS, et al: Pro-inflammatory cytokines and environmental stress cause p38 mitogen-activated protein kinase activation by dual phosphorylation on tyrosine and threonine. J Biol Chem 270: 7420-7426, 1995.

32. Chen P, Li J, Barnes J, Kokkonen GC, Lee JC and Liu Y: Restraint of proinflammatory cytokine biosynthesis by mitogenactivated protein kinase phosphatase-1 in lipopolysaccharidestimulated macrophages. J Immunol 169: 6408-6416, 2002.

33. Brondello JM, Pouyssegur J and McKenzie FR: Reduced MAP kinase phosphatase-1 degradation after p42/p44MAPK-dependent phosphorylation. Science 286: 2514-2517, 1999.

34. Sohaskey ML and Ferrell JE Jr: Activation of p42 mitogenactivated protein kinase (MAPK), but not c-Jun NH(2)-terminal kinase, induces phosphorylation and stabilization of MAPK phosphatase XCL100 in Xenopus oocytes. Mol Biol Cell 13: 454-468, 2002.

35. Cao W, Bao C, Padalko E and Lowenstein CJ: Acetylation of mitogen-activated protein kinase phosphatase- 1 inhibits Tolllike receptor signaling. J Exp Med 205: 1491-1503, 2008. 